\title{
IDIOPATHIC CYSTIC MEDIAL NECROSIS OF THE AORTA
}

\author{
BY \\ D. H. DAVIES \\ From the Cardiographic Department, Middlesex Hospital
}

Received April 2, 1941

Cystic necrosis of the aortic media is recognized as a cause of dissecting aneurysm and of spontaneous rupture of the aorta. Its occurrence in association with aneurysmal dilatation of the unruptured aorta is sufficiently rare to warrant the following case being reported.

\section{Clinical Report and Necropsy}

A man, aged 36, attended the out-patient department of the Middlesex Hospital in February 1940. He had never had rheumatic fever, chorea, or syphilis. Ten years previously he had first noticed dyspnœa on exertion and had been told at the time by his doctor that he had heart disease. During 1938 and 1939 he had become increasingly short of breath on effort, and for several weeks prior to coming to hospital he had suffered from paroxysms of nocturnal dyspnœa with blood-stained expectoration.

On examination he was breathless and orthopncic. The pulse was regular and collapsing; the brachial arteries normal; the blood pressure $150 / 60 \mathrm{~mm}$. The apex beat was in the mid-axillary line; systolic pulsation was visible in the second and third right intercostal spaces near the sternum; and systolic and diastolic thrills were palpable in the same area. A loud blowing diastolic murmur was heard on the left of the sternum and at the apex. There were widespread râles throughout both lung fields, but signs of systemic congestion were absent; the cervical veins were not engorged, the liver was not enlarged, and there was no œdema. The Wassermann reaction was negative.

$\mathrm{X}$-ray examination showed gross enlargement of the left ventricle, aneurysmal dilatation of the ascending aorta, and increased aortic pulsation (Fig. 1); there was no radiological evidence of mitral stenosis on screening. An electrocardiogram showed normal rhythm, with left axis deviation, a P-R interval of $0.20 \mathrm{sec}$., and inversion of the T waves in leads I and II.

The patient died in an attack of acute pulmonary œdema, four days after admission to hospital.

Necropsy.-(Permission was obtained for removal of the heart and lungs 


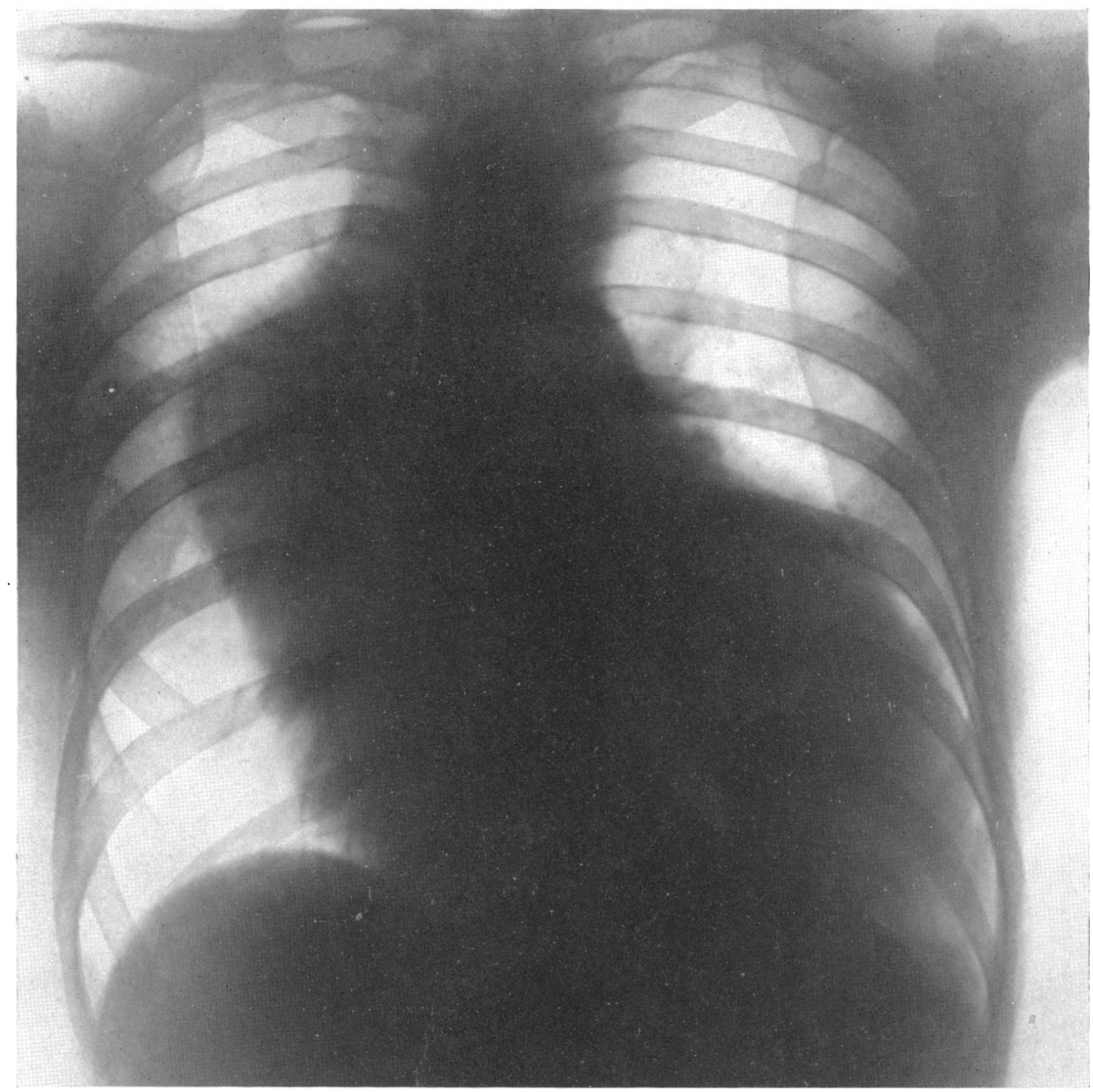

FIG. 1.-Radiograph showing aneurysmal dilatation of the ascending aorta and enlargement of the heart to the left.

only.) The heart weighed $27 \mathrm{oz}$ ( 765 g.). The left ventricle was both hypertrophied and dilated; the heart muscle was firm. The aortic ring was dilated, the valve cusps were thin and larger than normal, but appeared competent; the other valves were normal. The ascending aorta as far as the commencement of the innominate artery was uniformly dilated, measuring approximately $6 \mathrm{~cm}$. in diameter (Fig. 2). The wall of the aorta was slightly thinner than normal, and the intima was smooth. The coronary arteries were normal. Histological examination of the aorta showed cystic medial necrosis.

A histological report by Dr. R. W. Scarff, of the Bland Sutton Institute of Pathology, was as follows:-

"The main feature of sections (see Fig. 3), taken both at and below the lesion, is widespread degeneration of both muscular and elastic tissue with the formation of small cystic areas, containing mucoid material, which stains bluish with Mayer's hæmalum but does not give a positive muci-carmine stain. With Van Gieson's stain very little muscle can be found, and there is some fibrous tissue replacement, and no marked increase in the sub-endothelial fibrous 


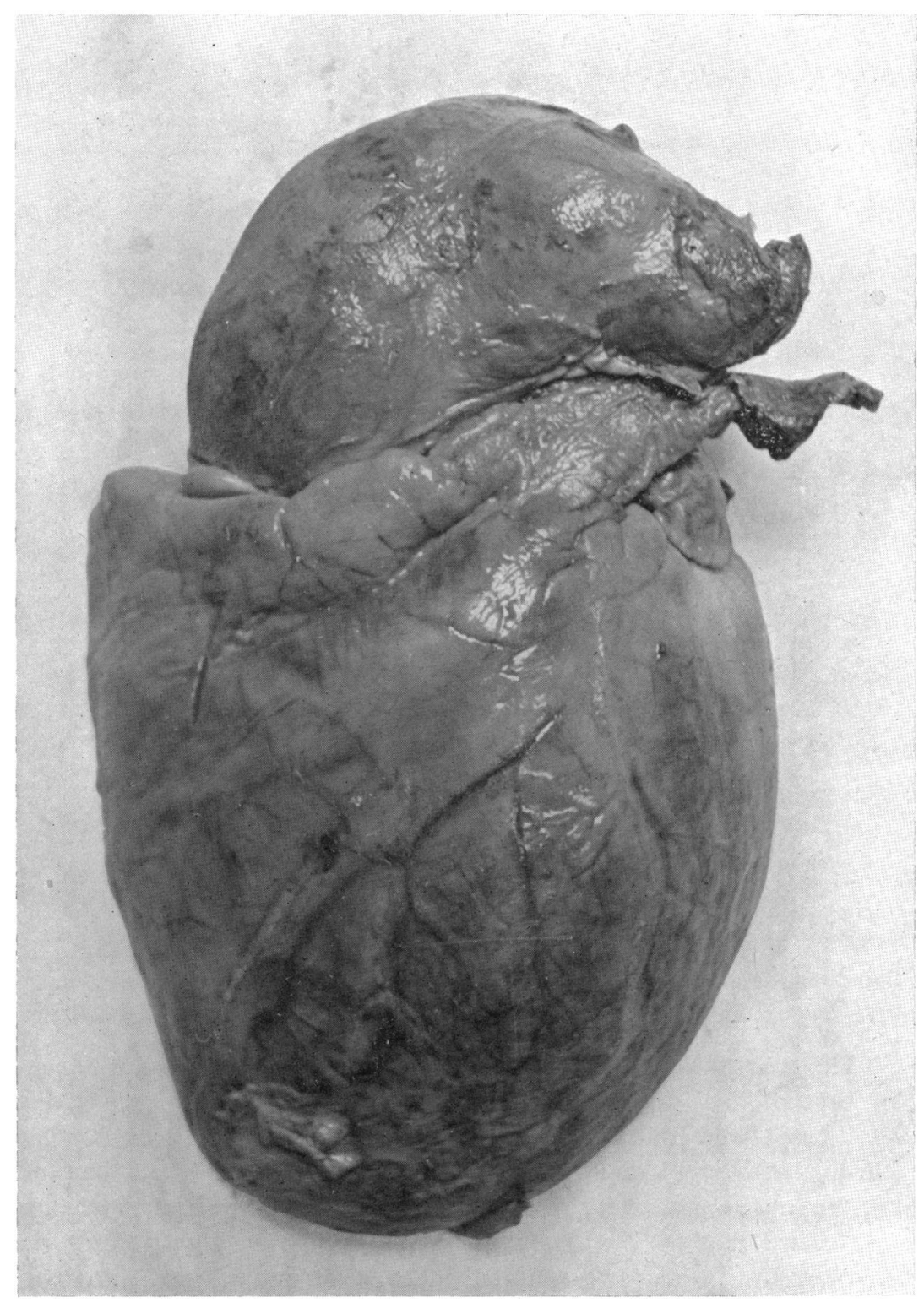

FIG. 2.-Photograph of the heart, post-mortem, showing a greatly dilated ascending aorta.

tissue. With Weigert's elastic stain there seems to be diminution in the elastic material, and complete absence of it in the extensive mucoid areas. In other parts of the section the elastic material appears as irregular short lengths of fibre which are fragmented; no internal or external lamellæ can be distinguished. The appearances are those of intense degeneration of musculo-elastic tissue with cystic areas and areas of fibrous replacement." (See Fig. 3.) 


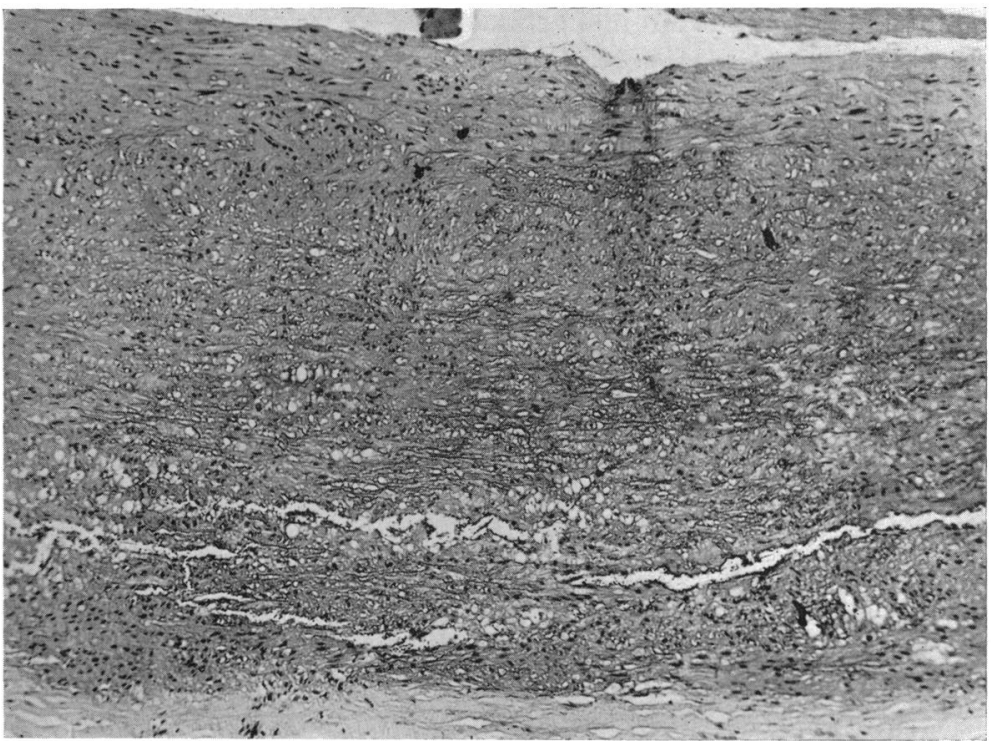

FIG. 3.-Section of the aorta showing areas of degeneration with cystic change. Magnification $\times 65$.

\section{DISCUSSION}

The clinical picture was that of terminal left ventricular failure in a man, aged 36, with aortic incompetence and aneurysmal dilatation of the aorta. The radiological appearances were suggestive of a syphilitic ætiology, though the history of heart disease of ten years' duration and the negative Wassermann reaction were against this. Cystic medial necrosis was not suspected.

Rottino (1940) stated that only 2 cases of cystic medial necrosis in unruptured aortas had been reported. Signs of aortic incompetence due to dilatation of the aortic ring have been observed in dissecting aneurysm (Resnik and Keefer, 1925), and a case of medial necrosis was described by Roberts (1939) in a man, aged 33, with dilatation of the aorta, aortic incompetence, and congestive failure; death was due to spontaneous rupture of the aorta. At necropsy, the aortic ring was dilated, and section of the aorta showed medial necrosis, the valves being normal. Rottino (1939) reported the case of a woman. aged 70, in whom the ascending aorta was diffusely dilated and thinwalled, and macroscopically the intima simulated syphilitic aortitis, but there were no murmurs of aortic incompetence. Dilatation of the ascending aorta with aortic incompetence occurred in Harrison's case (1939), but as coarctation was also present it is difficult to assess the part played by medial necrosis in causing the dilatation.

Medial necrosis is a common finding in cases of spontaneous rupture of the aorta. Glendy, Castleman, and White (1937) found it in 8 of 19 cases of ruptured aorta, and Klotz and Simpson (1932) in all of 5 cases, the youngest being a woman, aged 23, who was pregnant. Moritz (1932), examining routine unselected necropsy material, found medial necrosis in 6 of 70 cases, and 
Rottino (1939) found an even higher incidence-95 cases of medial degeneration in a total of 210, with cystic changes in 7 cases.

Since the first descriptions of cystic medial necrosis by Gsell (1928) and Erdheim (1929), detailed accounts of the pathology have been given by Moritz. (1932) and Rottino (1939, 1940).

The most advanced changes occur in the ascending aorta, especially at its root just above the valves; this is also the site of election for spontaneous rupture. The ætiology of the condition is still unknown. It was first thought to be a degenerative process associated with old age, but subsequent reports have shown that it occurs not infrequently in young people. Toxæmia, nicotine, hyperadrenalism, and hypertension have all been mentioned as factors. It is generally agreed that syphilis plays no part.

It is evident from the reports cited that cystic medial necrosis of the aorta is by no means excessively rare, and that it may cause diffuse dilatation of the ascending aorta and aortic incompetence. It should therefore be considered in the differential diagnosis of unexplained dilatation of the aorta.

\section{SUMMARY}

A case of idiopathic cystic medial necrosis of the aorta, without rupture, has been reported. The presenting signs were those of aneurysmal dilatation of the aorta with aortic incompetence and terminal left ventricular failure.

I have to thank Dr. G. E. S. Ward, Lieut.-Colonel Evan Bedford, and Dr. G. E. Beaumont for permission to publish this case, and Dr. R. W. Scarff for the histological report.

\section{REFERENCES}

Erdheim, J. (1929). Virchows Arch., 273, 454.

Gsell, O. (1928). Ibid., 270, 1.

Glendy, R. F., Castleman, B., and White, P. D. (1937). Amer. Heart J., 13, 129.

Harrison, F. F. (1939). Arch. Path., 27, 742.

Klotz, O., and Simpson, W. (1932). Amer. J. med. Sci., 184, 455.

Moritz, A. R. (1932). Amer. J. Path., 8, 717.

Resnik, W. H., and Keefer, C. S. (1925). J. Amer. med. Ass., 85, 422.

Roberts, J. A. (1939). Amer. Heart J., 18, 188.

Rottino, A. (1939). Arch. Path., 27, 321.

- (1940). Ibid., 28, 337.

- (1940). Amer. Heart J.. 19, 330. 